\title{
Geoelectric method applied in correlation between physical characteristics and electrical properties of the soil
}

\author{
Antonio Marcelino Silva Filho, Carlos Leandro Borges Silva, Marco Antonio Assfalk Oliveira, \\ Thyago Gumeratto Pires, Aylton José Alves, Wesley Pacheco Calixto, Marcelo Gonçalves Narciso \\ Federal University of Goias, Brazil
}

\begin{abstract}
This paper presents the study of the relationship between electrical properties and physical characteristics of the soil. Measures of apparent electrical resistivity of the soil were made for different types of soil, varying moisture content gradually while maintaining a constant compaction, and then varying the compaction and relating it to a constant humidity. Development of a correlation surface is proposed in order to identify granulometry of the soil from moisture and compaction measurements. For the study of spatial variability, two areas were chosen to allow the change of moisture content and compaction in order to verify the measurement capacity of apparent electrical resistivity of the soil as methodology to identify change in soil dynamics. Results obtained show correlations among apparent electrical resistivity of the soil, moisture, soil compaction and clay content.
\end{abstract}

Index Terms - Geoelectric prospecting, apparent electrical resistivity, soil compaction, moisture content.

\section{INTRODUCTION}

$\mathrm{S}_{\mathrm{a}}$ OIL can be considered as an electrical conductor having tortuous path or a large number of conduction paths with variable lengths and cross sections. Soil property to conduct electric current is called apparent electrical conductivity of the soil $\sigma_{a}$, which can be calculated from measurements of the voltage $V$ collected in field, after applying a current I to the soil.

Methods used in precision agriculture require fast and accurate answers to map the potential productivity of a given area [1]. One of the principles of precision agriculture is based on the property of soil to vary the apparent electrical conductivity according to variation of its physical and chemical properties such as texture, moisture, compaction, hydraulic potential, organic matter content, etc. For these reasons, apparent electrical conductivity of the soil has attracted the attention of researchers and investors for being a fast, noninvasive and inexpensive method [2]. In addition, investigations related to $\sigma_{a}$ can aid in the measurement of clay and water content [10].
On a plot, areas with homogeneous physical and chemical characteristics can be identified with the mapping of $\sigma_{a}$. With these values mapped geographically within land, it is possible to divide the regions in management areas and then proceed to collect some samples for analysis and, depending on their physical and chemical properties, make decisions on how to intervene with the inputs, pesticides and irrigation. The mapping of $\sigma_{a}$ is becoming an effective tool in the investigation of physical and chemical behavior and spatial variability of the soil, allowing to identify areas with similar properties and easily define management zones [3].

This paper strives to present the development of methodology to correlate soil electrical conductivity, soil moisture content $(w)$, clay content $(\delta)$ and soil compaction $(C)$.

The development of theoretical and experimental mechanism allowing abacus production for identification of soil granulometry from moisture and compaction measurements also comprises a goal of this paper.

\section{METHODOLOGY}

Electric conductivity is an intrinsic property of the whole electric current conductive material. In Geoelectric Prospecting, the conductor is the soil in which the electric current flows through the presence of free salts in the soil solution (liquid phase) and also due to the exchangeable ions in the particle surface [6].

However, unlike what happens with a wire conductor of electricity, the electric current in the ground can cycle through several ways, as illustrated in Fig. 1. In moist soils, the current conduction occurs mainly through the salt content in the soil water which occupies the largest pores, region 1 in Fig. 1. However, there are also solid phase contribution to the electrical conductivity in moist soils mainly by exchangeable cations associated with the clay mineral, region 2 in Fig. 1. A third path for electric current in the soil exists through particles in direct and continuous contact with each other, region 3 in Fig. 1. These three paths of current flow contribute to the overall electrical conductivity of the soil known as apparent electrical conductivity of the soil $\sigma_{a}$ [5]. 
Apparent electrical resistivity of the soil $\rho_{a}$ (which is the inverse of $\sigma_{a}$ ) is obtained through field measurements using geoelectric prospecting methods, the Wenner method [7].

The calculation of soil electrical resistivity is performed by an instrument which measures soil electrical resistance $R_{m}$ [8]. This instrument has four terminals, $T_{1}, T_{2}, T_{3}, T_{4}$, connected to four rods spiked at depth $P$ at the points $q_{1}, q_{2}, q_{3}, q_{4}$, aligned and separated by the same distance $a$. Electric current $I$ is injected into the terminal $T_{I}\left(q_{l}\right)$ and collected in the terminal $T_{4}\left(q_{4}\right)$, which produces electric potential $V$ at points $q_{2}$ and $q_{3}$. With $I$ and potential difference $V$ between $q_{2}$ and $q_{3}$, resistance $R_{m}$ can be calculated. Thus, apparent electrical resistivity of the soil $\rho_{a}[\Omega m]$ is given by [4]:

$$
\rho_{a}(a)=\frac{4 \pi a R_{m}}{1+\frac{2 a}{\sqrt{a^{2}+(2 P)^{2}}}-\frac{2 a}{\sqrt{(2 a)^{2}+(2 P)^{2}}}}
$$

This value $\rho_{a}$ varies with distance $a$, since the soils are heterogeneous. Thus, the magnitude happens to be called apparent electrical resistivity $\rho_{\mathrm{a}}(a)$ where the resistivity values are a function of $a[11]$.

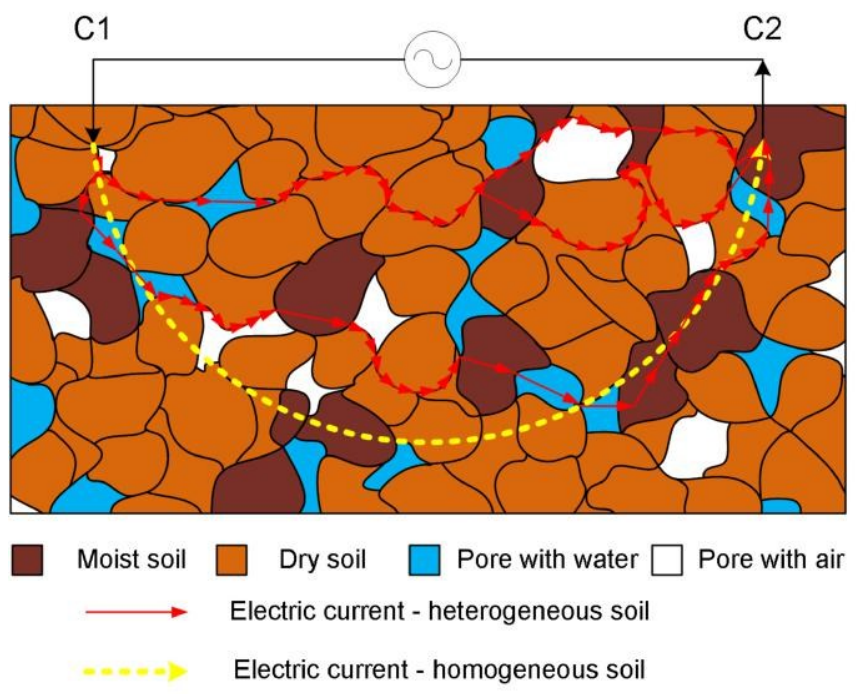

Fig. 1. Path of electric current in the soil.

\section{A. Lateral Profiling}

Lateral Profiling method is the geoelectric investigation technique used in the horizontal mapping, which consists of the relocation of electrodes in the following points at each measurement, keeping a fixed distance among the rods [9]. Wenner array is used for the application of this technique, where apparent electrical conductivity of the soil $\sigma_{a}$ is determined at midpoint of the arrangement between potential electrodes. Entire area can be mapped by identifying these midpoints, delimiting different conductivity regions.

Fig. 2 illustrates the technique for research. In this case, the method applies in column 1 at A1, B1, C1 and D1. In this example the Wenner method is used to apply the Lateral Profiling. The horizontal mapping of apparent electrical conductivity is determined by performing electrical pathway of columns 2,3 and 4 .
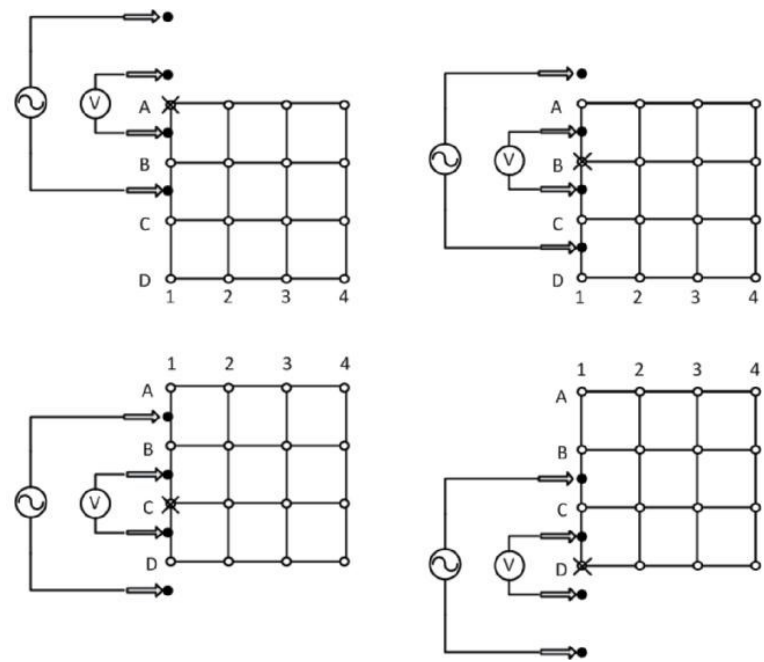

Fig. 2. Lateral Profiling Method.

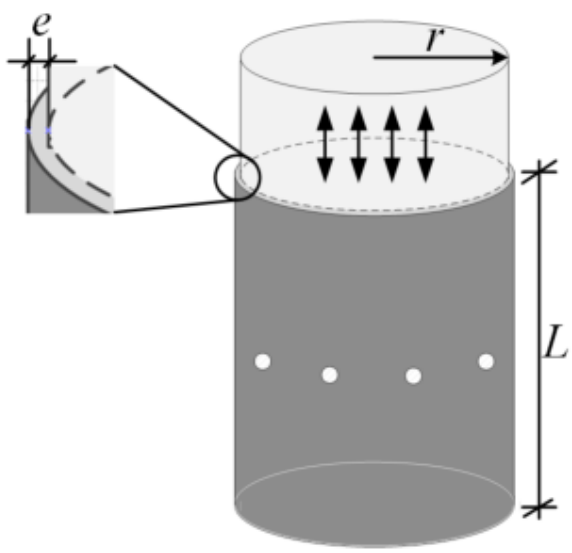

Fig. 3. PVC cell.

\section{B. Experimental procedure - Laboratory Study}

For the application of the proposed methodology, a PVC container (cell) is built in order to contain the soil samples. Constructed cell has $r=37,5 \mathrm{~mm}$ internal radius, $L=80 \mathrm{~mm}$ height, wall thickness of $e=4 \mathrm{~mm}$ and 4 holes for insertion of current and potential electrodes for the application of Wenner arrangement, as illustrated in Fig. 3.

\section{1) Sample Preparation}

Sample preparation consists in doping the same with known amounts of clay. From the sandy soil, samples are prepared with different proportions of clay, varying the texture of each sample.

Each portion (sample) must contain the same mass. In each portion, withdraws certain amount of soil and inserts the same amount of clay, in order to obtain samples with a known clay content. For example, to prepare the sample with clay content of $20 \%$, it is weighed initially the full portion of collected soil 
TABLE I

GRANULOMETRIC ClASSIFICATION OF THE SAMPLES

\begin{tabular}{cc}
\hline \hline $\begin{array}{c}\text { Clay } \\
\text { [\%] }\end{array}$ & $\begin{array}{c}\text { Granulometric } \\
\text { Classification }\end{array}$ \\
\hline 0 & Sand \\
20 & Sandy Loam \\
40 & Sandy Clay Loam \\
60 & Sandy Clay \\
80 & Sandy Clay \\
100 & Clay \\
\hline \hline
\end{tabular}

and withdraws the equivalent of $20 \%$ of its weight, inserting in place the same amount of clay, in order to obtain the sample doped with $20 \%$ clay.

This methodology is adopted in order to obtain samples with a gradual variation in granulometric classification of the soils. After this doping step, samples were sent to laboratory for analyze granulometric classification of the same. The Tab I provides the classification results.

\section{2) Relation among electrical resistance $\left(R_{m}\right)$, soil moisture} (w) and clay content $(\delta)$

Relationship among electrical resistance of the soil $R_{m}$, soil moisture $w$ and the clay content $\delta$ consists of performing $R_{m}$ measures in soils with different clay content, gradually varying the moisture content, keeping the compaction $C$ constant

The $R_{m}$ values are obtained from geoelectrical prospection methods which detect effects produced by the flow of electric current in the soil. Method of geoelectric prospection utilizes Wenner arrangement for data collection, where electric current is injected and captured in the soil by current electrodes, and voltage is measured at two points of surrounding region by potential electrodes.

Soil samples are first taken to the oven (heater) in order to reduce moisture levels to values close to $0 \%$. After passing through the desiccator cooling process, it is gradually added portions of water equivalent to $5 \%$ of the mass of the dry sample. At each increment of water portion to the sample, the corresponding value of electrical resistance $R_{m}$ is measured by the electrical resistivity meter as illustrated in Fig. 4(a). For each sample, the compaction load is constant.

\section{3) Relation among electrical resistance $\left(R_{m}\right)$, soil compaction $(C)$ and clay content $(\delta)$}

The practical experiment to relate $R_{m}, C$ and $\delta$ consists of performing $R_{m}$ measurements in soils with different clay content, gradually varying the compaction $C$ keeping moisture content $w$ constant.

Soil samples are taken to the oven (heater) and cooled in desiccator. After passing through the cooling process, all samples are gradually moistened until they have constant moisture, $w \approx 20 \%$.

At each increase in compaction values, the corresponding value $R_{m}$ is measured by the electrical resistivity meter.
Apparatus of Fig. 4(b) is designed in order to apply pressure on the sample that is within the PVC cell. Under the PVC cell, it places the scale to measure the force exerted on the sample. $R_{m}$ is measured at each increment of $1 \mathrm{~kg}$ in compaction.

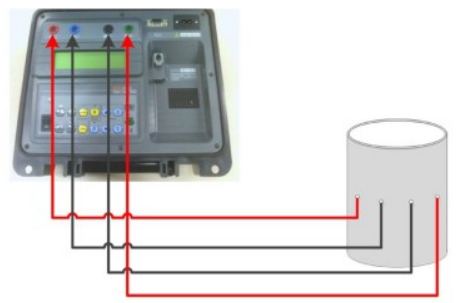

(a)

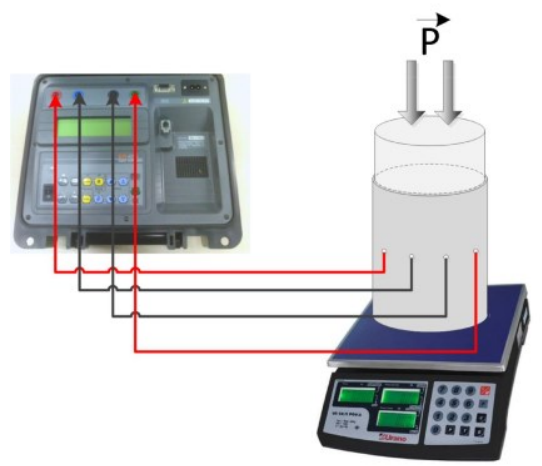

(b)

Fig. 4. PVC cell connected to electrical resistivity meter: (a) $R_{m} x w x \delta$ and (b) $R_{m} x C x \delta$.

\section{Experimental procedure - Field Study}

Two areas are chosen to enable the change of moisture content and compaction, in order to verify the measurement capability of $\rho_{a}$ to identify changes in soil dynamics. Wenner method is used along with Lateral Profiling method for determining $\rho_{a}$. The entire area is mapped in the state it is in. One sub-region within the area should be chosen, where water should be added (sub-region with different color in Fig. 5), modifying the moisture. Again, the survey of $\rho_{a}$ is performed in the same region. This same methodology can be applied to the mapping of the soil penetration resistance by simply, instead of adding water to modify the dynamics of the system, change the soil compaction.

\section{RESULTS}

The soil for laboratory analysis was classified as Gleysol and collected in location S1346'14.5" W5048'16.1".

A. Relation among electrical resistance $\left(R_{m}\right)$, soil moisture $(w)$ and clay content $(\delta)$

Fig. 6 illustrates equipment and connections used to analyze the correlation $R_{m} x \quad w \quad x \quad \delta$, where red cables are electrical current injection electrodes and black cables are electrical potential electrodes. Initially, the humidity of each sample is measured by moisture meter, in order to verify whether soil samples are with humidity values near $0 \%$. Then, the mass of 
each dry sample is measured in order to calculate the mass of water corresponding to be inserted gradually in the sample.

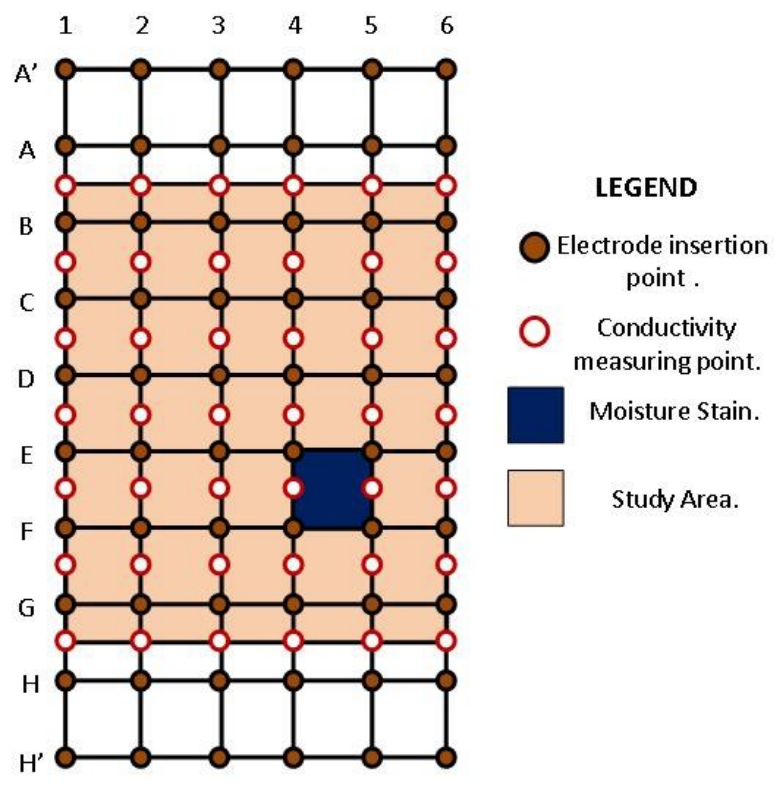

5. Delimited area for the application of Lateral Profiling method.

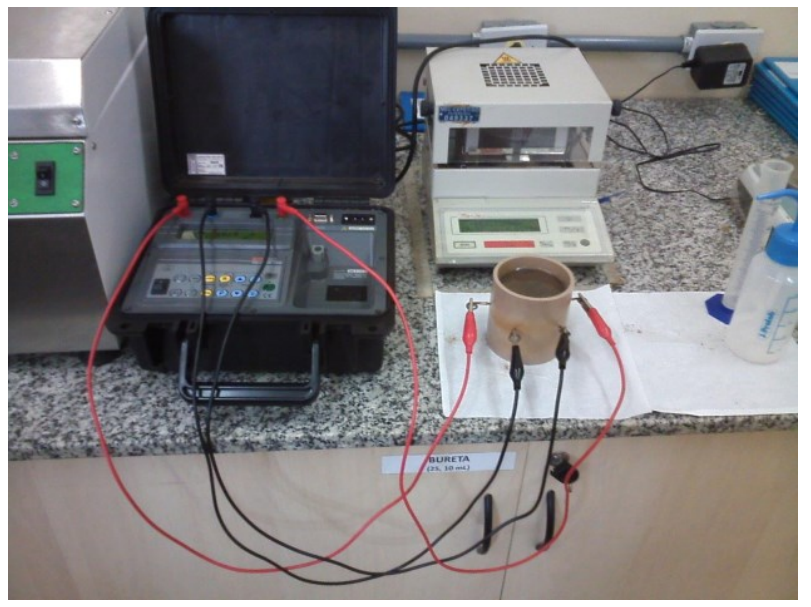

Fig. 6. Equipment for the analysis of correlation $R_{m} x w x \delta$.

At each insert 5\% water portion, resistance $R_{m}$ is measured with electrical resistivity meter, for each one of the 6 samples.

In any sample could be obtained value of $R_{m}$ for dry soil, therefore, for this situation the resistance value is greater than the set full scale. Values of $R_{m}$ were obtained for moisture contents above $w=10 \%$, except for Gleysol sample. This type of soil allows to obtain resistance values at lower moisture levels by their sandy granulometry, which, due to its porosity, facilitates the circulation of electric current through the liquid phase located in the larger pores.

Fig. 7(a) shows the curves of 6 soil types under study in order to evaluate the effect of moisture $w$ and clay content in $R_{m}$ values.

Resistance $R_{m}$ varies considerably with the change of soil moisture content $w$ and clay content $\delta$ (Fig. 7(a)). Maintaining constant compaction, electrical resistance $R_{m}$ decreases with increasing moisture and clay content. Due to the grain size, the sandy sample ( $0 \%$ clay) has a higher pore area than the other samples. With increased moisture content, these spaces occupied by air become occupied by water allowing smaller values of $R_{m}$ with increasing humidity, resulting in high percentage value in the reduction of electrical resistance $R_{m}$.

B. Relation among electrical resistance $\left(R_{m}\right)$, soil compaction (C) and clay content $(\delta)$

Apparatus of Fig.8 was developed to apply pressure on the samples for the experiment of correlation $R_{m} \times C \times \delta$. A scale placed below the cell performed measurements of the force applied on the sample. It changed gradually the pressure, in order to perform measurements $R_{m}$ at each $1 \mathrm{~kg}$ of applied load. Pressure applied to the soil sample is calculated through the value read on the scale. Red cables in Fig. 8 are electrical current injection electrodes and black cables are electrical potential electrodes.

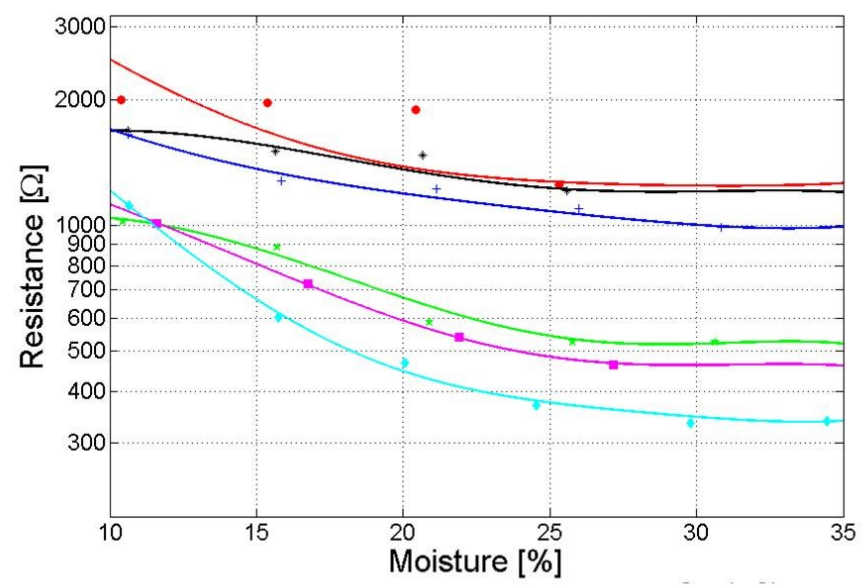

(a)

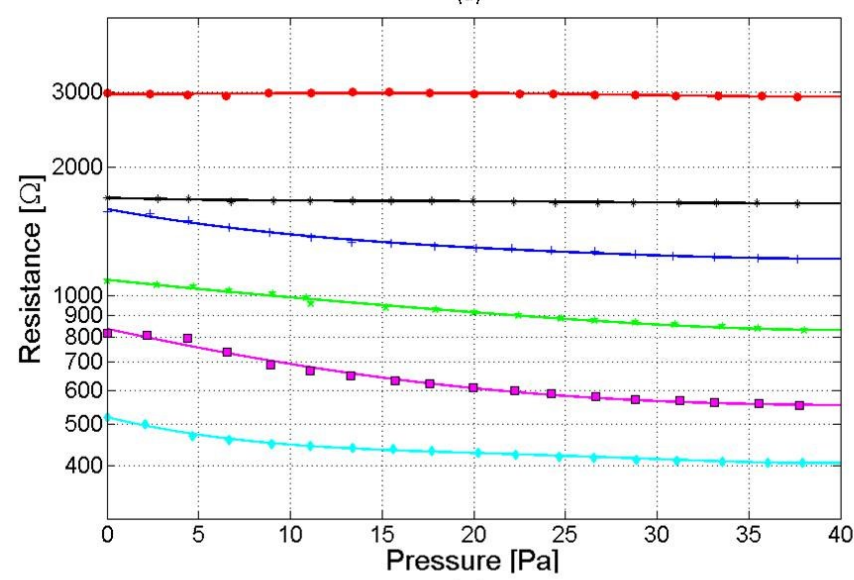

(b)

$$
\begin{array}{lll}
\text { - Sand } & \text { Sandy Clay } & \text { Sandy Clay } \\
\text { - Values - Sand } & \text { ¿ Values - Sandy Clay } & \text { Values - Sandy Clay } \\
\text { - Sandy Loam } & \text { - Sandy Clay Loam } & \text { Clay } \\
\text { * Values - Sandv Loam + Values - Sandy Clay Loam } & \text { - Values - Clay }
\end{array}
$$

Fig. 7. Correlation Curves: (a) $R_{m} x w x \delta$ and (b) $R_{m} x C x \delta$

Fig. 7(b) shows the curves of the 6 soil types under study in order to verify the effect of compaction $C$ and clay content $\delta$ in $R_{m}$ values. Each $1 \mathrm{~kg}$ load applied, the resistance $R_{m}$ is 
measured by earth meter for each of the 6 samples. For all of them, humidity is approximately constant $w \approx 20 \%$.

Resistance decreases with increasing clay content and the increase in the levels of soil compaction, particularly on soils with greater presence of clay fractions in its constitution. For samples of sandy soil and sandy loam soil, where there is a predominance of sand fractions, the influence of compaction on $R_{m}$ values was lower when compared to samples with higher clay content, indicating $R_{m}$ behaves differently for sandy and clay soils.

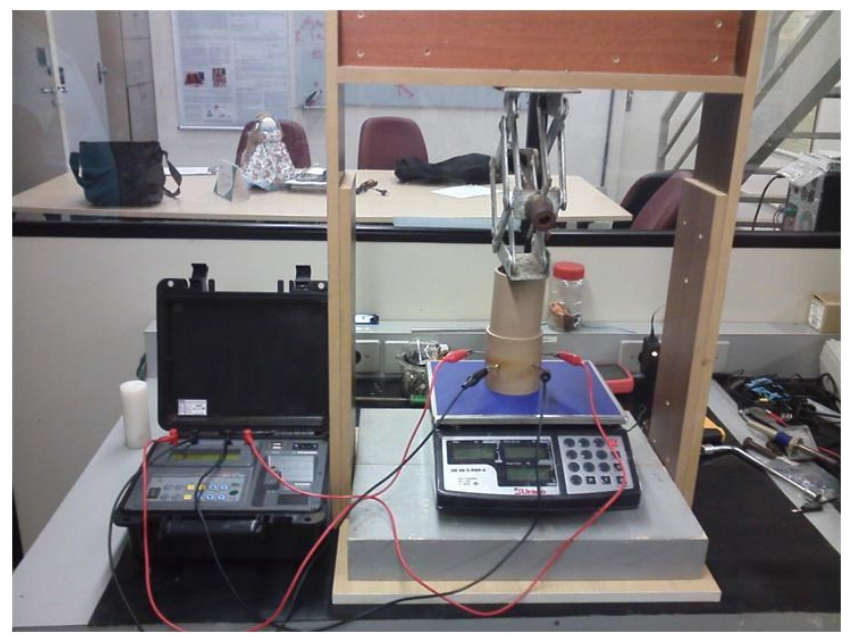

Fig. 8. Apparatus developed for the analysis of correlation $R_{m} x C x \delta$.

\section{Correlation Surface}

With the data of Fig. 7, correlations can be established among resistance $R_{m}$, moisture, soil compaction and clay content in order to facilitate the identification of soil granulometry from moisture and compaction measurements. Fig. 9 shows the correlation surface $R_{m} \times C \times w \times \delta$, where the plane $x, y$ represents the relationships $R_{m} \times w$ and $R_{m} \times C$ and the $z$ axis represents the clay content. On this surface, the data used were the saturation, or the average moisture of $w=28,99 \%$ and average compaction of $C=37,78 \mathrm{kPa}$. The color grading in the figure corresponds to granulometric variation of soil.

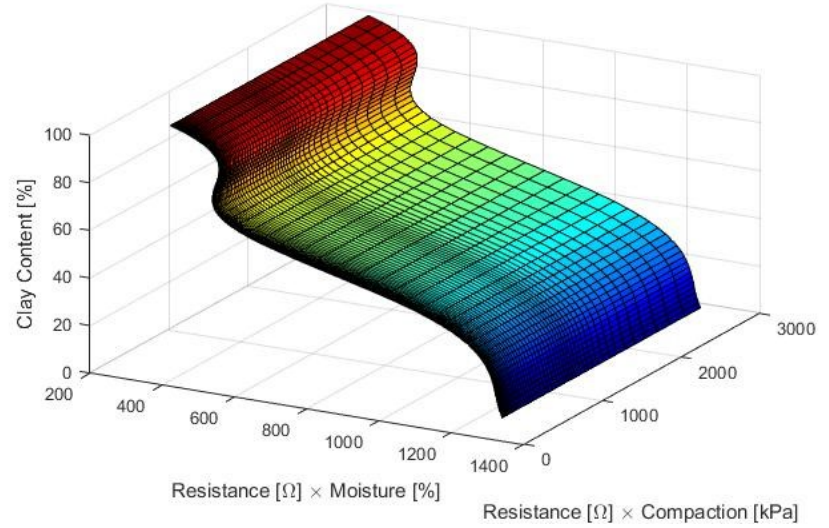

Fig. 9. Correlation Surface.
From the saturation data of $R_{m}$ in Fig. 7, clay content can be determined through the correlation surface. For example, in the case of moisture saturation was obtained $R_{m}=1252 \Omega$ (Fig. 7(a)), while for the case of compaction saturation was obtained $R_{m}=2930 \Omega$ (Fig. 7(b)). With these two points in the $x, y$ plane, clay content in $z$ axis can be obtained from correlation surface (Fig. 9). Note that the value found is $\delta=$ $0 \%$, or sandy soil. Thus, for the case of an argisoil with moisture content $\mathrm{w} \approx 28 \%$ and compaction $C \approx 37 \mathrm{kPa}$, granulometry of the soil can be identified on the correlation surface. For this, the use of Tab I is required, which defines the intervals: $0 \% \approx 20 \%$ sand soil; $20 \% \approx 40 \%$ sandy loam soil; $40 \% \approx 60 \%$ sandy clay loam soil; $60 \% \approx 100 \%$ sandy clay soil and equal to $100 \%$ clay soil.

\section{Identification of soil moisture stains through Lateral Profiling method.}

The region defined for the study has 5 meters long and 5 meters wide. Lateral Profiling was used with spacing $a=1 \mathrm{~m}$ and $P=20 \mathrm{~cm}$ depth. With data of $R_{m}$ and through equation 1 , the apparent resistivity matrices before and after the insertion of water are produced, Fig. 10(a) and Fig. 10(b) respectively.

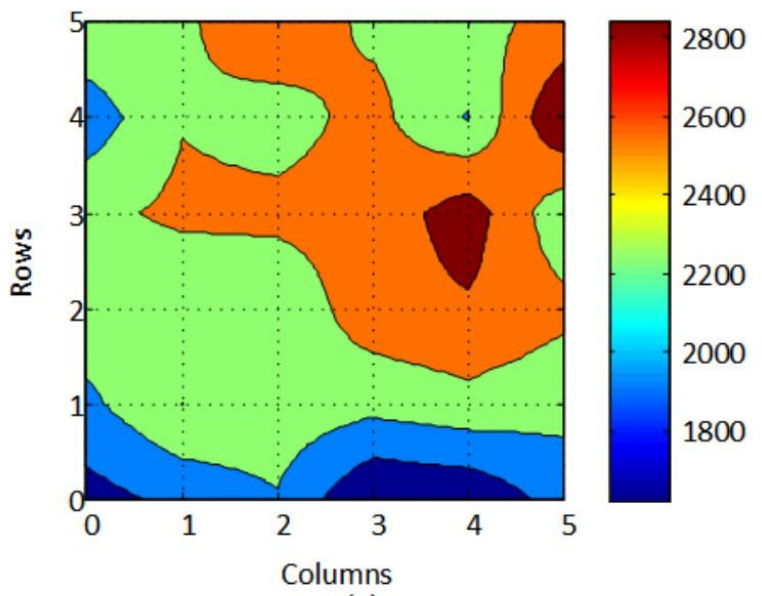

(a)

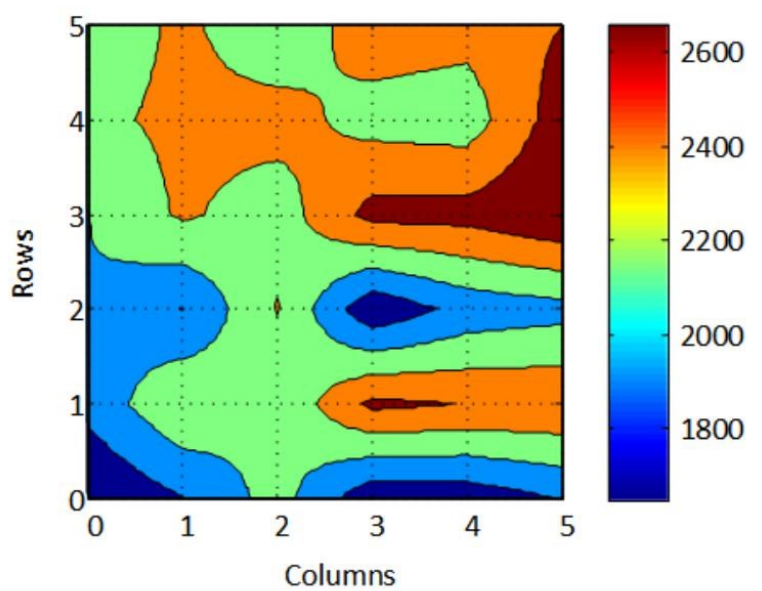

(b) 
Fig. 10. Moisture stains mapping through Lateral Profiling method $\left(\rho_{a}\right)$.

The colors of Fig. 10(a) and Fig. 10(b) represent areas with homogeneous physical and chemical characteristics. Each of these 5 color shades are associated to soil portion with same properties. To map the soil of this region, for example, would be required to collect 5 soil samples to be analyzed in laboratory, perform soil mapping and, based on their physical and chemical properties, make decisions about management of inputs, pesticides and irrigation.

Fig. 11(a) demonstrates the dynamics occurred in the system, obtained by subtracting of matrices from Fig. 10(a) and Fig. 10(b). Formation of isolines are observed in region where water was added, showing that proposed method has sensitivity to detect differences in apparent electrical resistivity of the soil, mapping its dynamics.

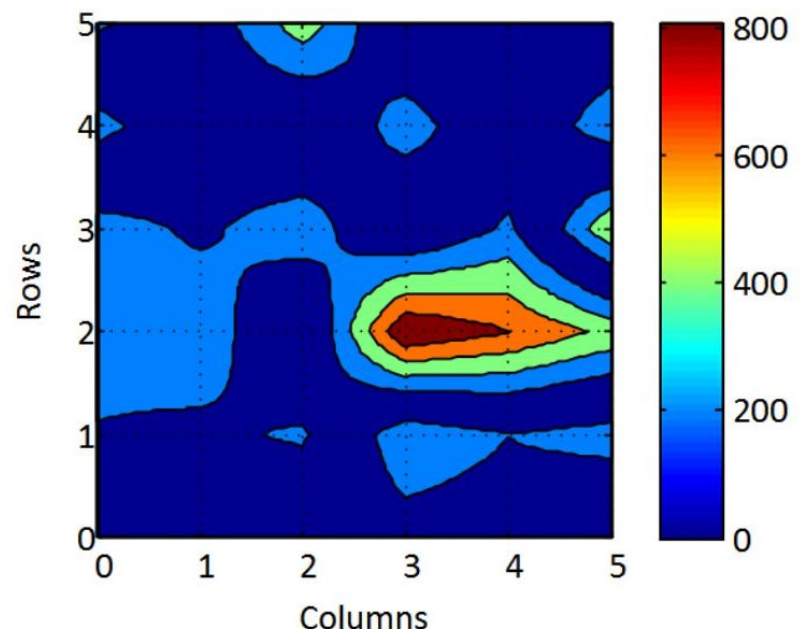

(a)

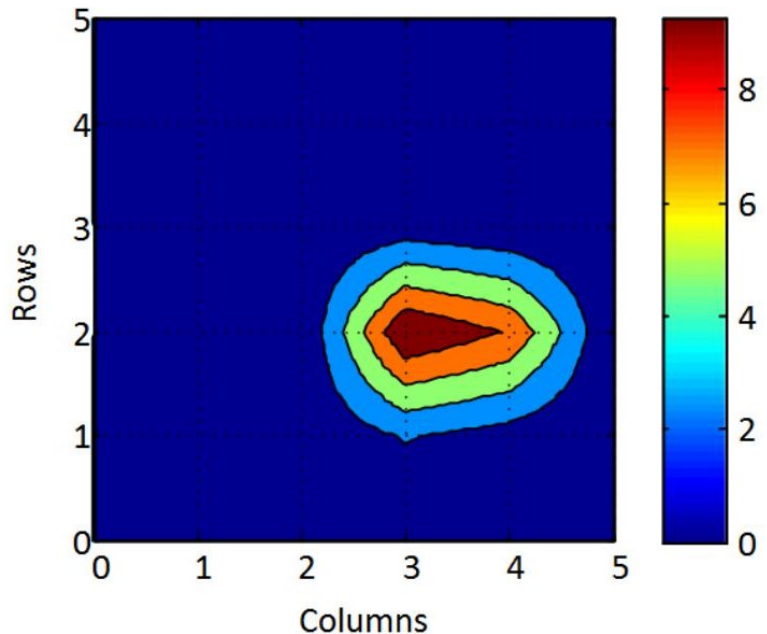

(b)

Fig. 11. Moisture stains mapping: (a) proposed method and (b) moisture meter TDR.

In this same area and at the same time it was used a Time-Domain Reflectometer (TDR) to measure the soil moisture content in order to compare the results found in the proposed method.

Fig. 11(b) shows the result obtained by TDR, after subtraction of data measured before and after insertion of the water.

The proposed method, Fig. 11(a), obtains more details than TDR, Fig. 11(b), indicating the proposed method is more sensitive than TDR.

\section{E. Identification of soil compaction stains through Lateral Profiling method.}

In another region, soil compaction is changed, using the same proposal, producing matrices before and after compaction. Fig. 12(a) represents apparent electrical resistivity data collected for original soil conditions and Fig. 12(b) represents measured values for soil after compaction.

As in Section III-D, each of 5 colors shades are associated to soil portion with same properties allowing, analogously, the mapping of spatial variability of the soil.

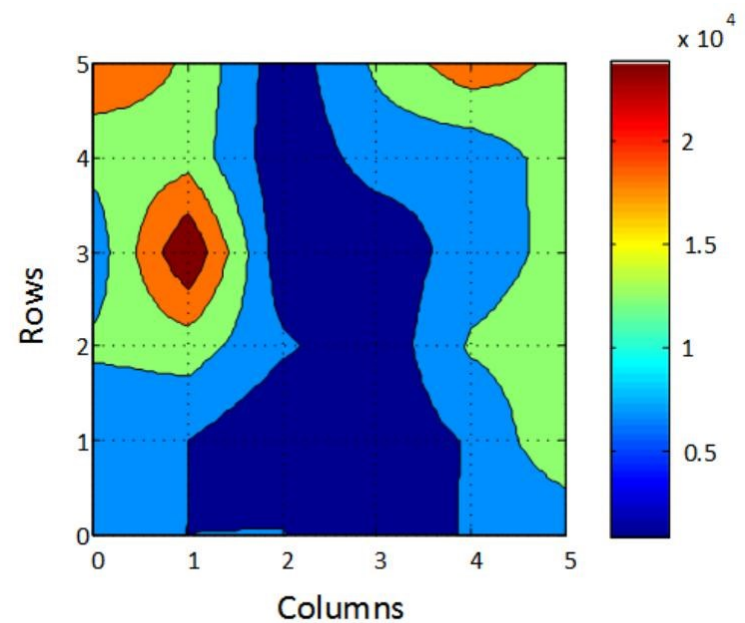

(a)

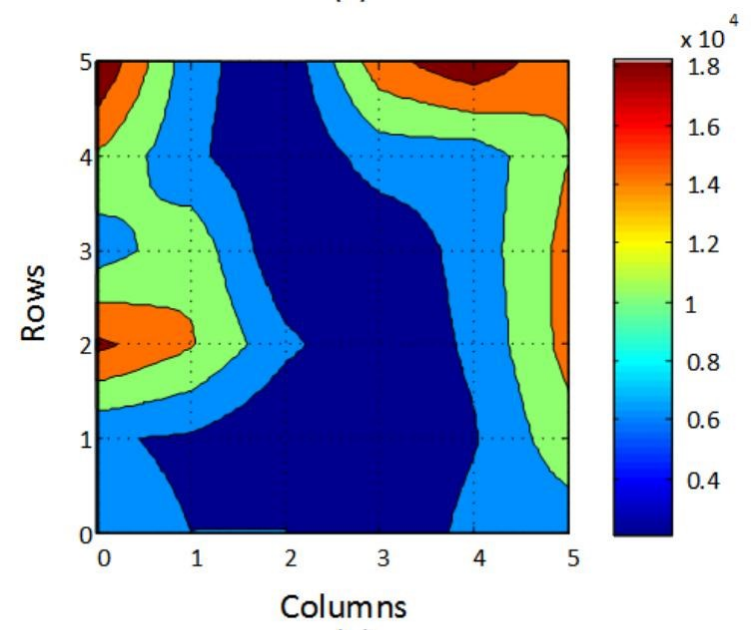

(b) $\left(\rho_{a}\right)$.

Fig. 12. Compaction stains mapping through Lateral Profiling method

Fig. 13(a) shows the result of the difference between the matrices before (Fig. 12(a)) and after (Fig. 12(b)) compaction in subregion of study area. Hot colors of Fig. 13(a) represents the differences occurred in dynamics of the area where soil was compacted, showing that stain 
compaction was detected by measuring of apparent electrical resistivity of the soil.

In this same area and at the same time a digital penetrometer was used to measure soil compaction in order to compare the results found by the proposed method. Thus, using the digital penetrometer, soil compaction was measured before and after the change of the dynamic, generating two matrices. Fig. 13(b) shows result of the subtraction of these two matrices. Again, it is observed that proposed method has isolines with greater precision details, see relationship between the curves of Fig. 13(a) and (b).

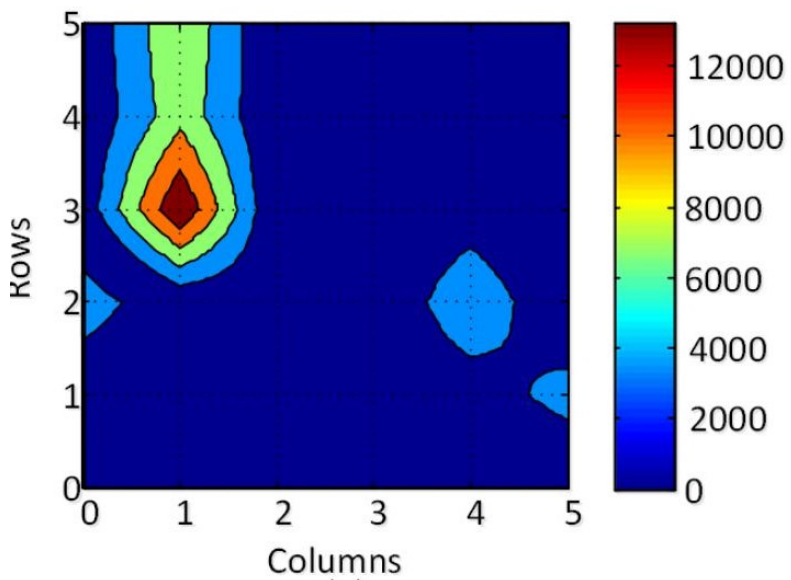

(a)

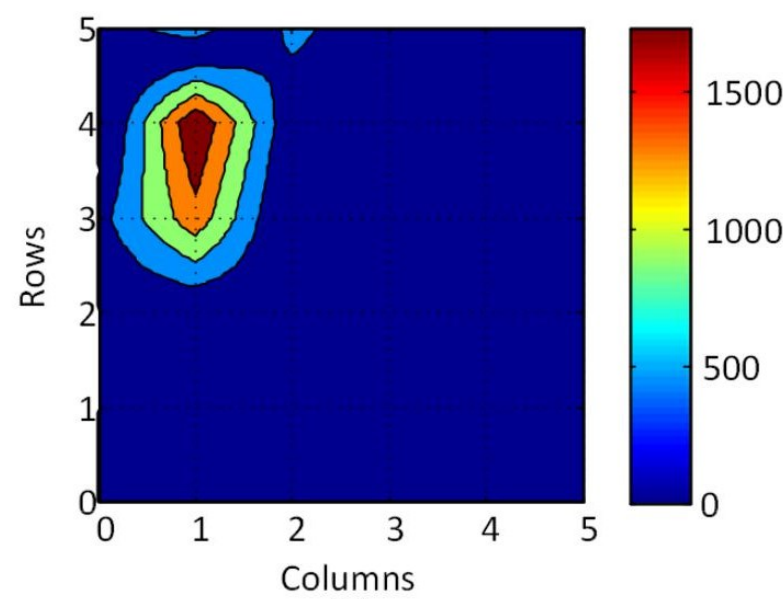

(b)

Fig. 13. Compaction stains mapping: (a) proposed method and (b) penetrometer.

\section{CONCLUSIONS}

The main purpose of this work was to develop methodology for correlating water content in soil, clay content and compaction with electrical properties of the soil, measured by geoelectrical prospecting methods. Resistance $R_{m}$ varies considerably with the change in moisture content of the soil $w$. $R_{m}$ also decreases with increasing $w$ and the measured resistance decreases with increasing clay content. Clay soils conduct better than sandy soils. The compaction $C$ influences the values of $R_{m}$, especially for samples with higher clay content, but at a lower degree than the moisture $w$. Through the Correlation Surface (Fig. 9) it is possible to correlate electrical resistance of the soil, moisture, soil compaction and clay content in order to identify the granulometry of the soil.

Field experiments indicate that Lateral Profiling method is appropriate for measuring regions with same characteristics. These experiments were able to accurately measure the change in soil dynamic produced intentionally. The proposed method is more accurate both in detecting moisture as in detection of soil compaction. The Lateral Profiling method is more sensitive to plot curves and, from correlation abacus, humidity values and compaction can be inferred directly on readings of apparent electrical resistivity of the soil.

Another observation subject of argumentation is related to different color shades of Fig. 10 and Fig. 12. Each tonality is associated to specific soil area with different physical and chemical characteristics. In possession of this georeferenced surface it is possible to proceed data collect on the regions of different shades and utilizing the consideration that the same tonalities has the same physical and chemical characteristics, considerably reduce the amount of sample collection and the number of laboratory analysis. Thus, Lateral Profiling is a noninvasive, fast and low cost method for mapping spatial variability of the soil, supporting decision making on how and when to intervene with inputs, pesticides and irrigation.

\section{ACKNOWLEDGMENT}

The authors would like to thank Coordination for the Improvement of Higher Education Personnel (CAPES), the National Counsel of Technological and Scientific Development (CNPq) and Research Support Foundation of Goias State (FAPEG) for financial support research and scholarships.

\section{REFERENCES}

[1] E.D. Lund, P.E. Colin, D. Christy, and P.E. Drummond. Applying Soil Electrical Conductivity Technology to Precision Agriculture. Saint Paul: Proceedings ASA/CSSA/SSSA, 1998.

[2] A. Tabbagh, M. Dabas, A. Hesse, and C. Panissod. Soil resistivity: A Non-invasive Tool to Map Soil Structure Horizontal. Geoderma, vol.97, p. 393-404, 2000.

[3] E.L. Eisenreich. Electrical Conductivity Mapping for Precision Agriculture. Proceedings. Montpellier, Ecole National Superiure Agronomique: European Conference on Precision Agriculture, v. 3, 2001.

[4] A.M. Silva Filho, G.P. Furriel, W.P. Calixto, A.J. Alves, F.A. Profeta, J.L. Domingos, E.G. Domingues, and M.G. NARCISO. Methodology to Correlate the Humidity, Compaction and Soil Apparent Electrical Conductivity. IEEE Congreso Chileno de Ingenieria Electrica, Electronica, Tecnologias de la Informacion y Comunicaciones (IEEE CHILECON 2015), 2015, Santiago. ACTAS de IEEE Chilecon 2015, Universidad Central de Chile, p. 1-7, 2015.

[5] D.L. Corwin and S.M. Lesch. Application of soil electrical conductivity to Precision Agriculture:Theory, Principles, and Guidelines. Agronomy Journal, v.95, n.3, 2003.

[6] S. P. Friedman. Soil properties influencing apparent electrical conductivity: a review. Computers and electronics in agriculture, 2005.

[7] W.M. Telford, L.P. Geldart, and R.E. Sheriff. Applied Geophysics, Cambridge University Press, 1990.

[8] J.D. Rhoades, and R.D. Ingvalson. Determining Salinity in Soils with Soil Resistance Measurements. Soil Science of American Proceedings, vol.35, 1971 . 
[9] O. Banton, M.K. Seguin, and M.A. Cimon. Mapping Field-Scale Physical Properties of Soil with Electrical Resistivity. Soil Science Societies American Journal, vol.61, 1a. ed. SSSAJ, 1997.

[10] B.G. Williams, and D. Hoey. The use of electromagnetic Induction to Detect the Spatial Variability of the Salt and Clay Content of Soil. Australian Journal of Research, v.25, n.1, p.21-7, Melbourne, 1987.

[11] W.P. Calixto, A.P. Coimbra, B. Alvarenga, J.P. Molin, A. Cardoso, and L. Martins Neto. 3-D Soil Stratification Methodology for Geoelectrical Prospection. IEEE Transactions on Power Delivery, v. 27, p. 1636-1643, 2012. 